\title{
The Role of TGF- $\beta$ Signaling in $\beta$-Cell Dysfunction and Type 2 Diabetes: A Review
}

\author{
Shane Fischbach ${ }^{1,2}$ and George K. Gittes ${ }^{1^{*}}$ \\ ${ }^{1}$ Division of Pediatric Surgery, Children's Hospital of Pittsburgh, University of Pittsburgh School of Medicine, Pittsburgh, PA 15224, USA \\ ${ }^{2}$ Division of Biology and Medicine, Brown University, Providence, RI, 02912, USA
}

"Corresponding author: George K. Gittes, Division of Pediatric General and Thoracic Surgery, 4401 Penn Avenue, Pittsburgh, PA 15224, USA, Tel: (412) 692-7280, Fax: (412) 692-6069, E-mail: Gittesgk@upmc.edu

Rec date: Aug 14, 2014, Acc date: Sep 27, 2014, Pub date: Sep 29, 2014

Copyright: ( 2014 Fischbach S, et al. This is an open-access article distributed under the terms of the Creative Commons Attribution License, which permits unrestricted use, distribution, and reproduction in any medium, provided the original author and source are credited.

\begin{abstract}
Type 2 Diabetes (T2D) is a global epidemic that affects hundreds of millions of individuals. The pancreatic $\beta$-cell has long been the focus of studies pertaining to T2D, but the therapies that exist to date are inadequate. Devising new therapies will require a more detailed understanding of the pathogenesis of T2D and of the normal function of the $\beta$-cell. In particular, there is a great need to understand the signaling pathways that govern normal $\beta$-cell function and that become dysfunctional during the progression to diabetes.

The Transforming Growth Factor $\beta$ (TGF- $\beta$ ) signaling pathway is implicated in nearly all tissue types in the body, and has been shown to play a role in pancreas development and homeostasis, including $\beta$-cell regeneration after pancreatic insult. TGF- $\beta$ exerts its cellular effects through transcriptional activity of downstream SMAD molecules, as well as through cross-talk with other signaling pathways.

Accumulating evidence suggests that $\beta$-cell failure in T2D is a multifaceted process that may include islet inflammation, increased $\beta$-cell apoptosis, reduced $\beta$-cell proliferation, and/or $\beta$-cell dedifferentiation to a progenitorlike state. This review details the known roles of TGF- $\beta$ signaling in dedifferentiation-induced and inflammationinduced $\beta$-cell failure, and draws on the apparent coordinated regulation of $\beta$-cell proliferation and the $\beta$-cell differentiation state to offer new hypotheses about $\beta$-cell failure in T2D.
\end{abstract}

Keywords: Transforming Growth Factor- $\beta$ (TGF- $\beta$ ); SMADs; Glucotoxicity; Nuclear factor kappa-light-chain-enhancer of activated $B$ cells (NF- $\kappa \mathrm{B})$; Type 1 Diabetes; Type 2 Diabetes

\section{Introduction}

Investigations of $\beta$-cell biology have shed light on the pathogenesis of Diabetes Mellitus, a heterogeneous group of disorders characterized by inadequate glucose-stimulated insulin secretion (GSIS) and hyperglycemia. The resulting dysfunctional glucose homeostasis predisposes diabetic patients to nephropathies, retinopathies, neuropathies and vasculopathies, which present serious long-term physiological risks.

There have been extensive studies of the molecular mechanisms that underlie proper $\beta$-cell function, as well as $\beta$-cell dysfunction and $\beta$-cell failure in both autoimmune diabetes (Type 1 Diabetes, T1D) and obesity-related diabetes (Type 2 Diabetes, T2D). The intracellular signaling pathways that govern $\beta$-cell function represent an attractive therapeutic target in diabetes, but a better understanding of many of these important pathways is still needed.

TGF- $\beta$ isoform signaling plays a central role in mammalian tissue development, homeostasis, and disease [for a comprehensive review of TGF- $\beta$ superfamily signaling, $[1,2]$. In short, a TGF- $\beta$ ligand (TGF- $\beta 1$, 2 or 3 in mammals) binds to the serine/threonine kinase receptor TGF- $\beta$ Receptor Type 2 (TGF $\beta$ RII), which phosphorylates and activates TGF- $\beta$ Receptor Type 1 (TGF $\beta$ RI). This phosphorylation leads to phosphorylation of receptor-regulated R-SMAD molecules,
SMAD2 and SMAD3, followed by nuclear translocation and transcriptional R-SMAD activity. Activation of these downstream effectors is inhibited by SMAD6 and/or SMAD7.

In addition to negatively regulating TGF- $\beta$, Activin and Bone Morphogenetic Protein (BMP) signaling (essentially all TGF- $\beta$ superfamily signaling), SMAD7 also leads to interactions between TGF- $\beta$ and other signaling pathways, including MAPKs (p38, ERK and JNK). SMAD7 also mediates cross-talk between TGF- $\beta$ signaling and the inflammatory pathways initiated by IFN $-\gamma$ and TNF- $\alpha$. The function of SMAD7 is largely context-dependent, but includes regulation of apoptosis and fibrosis in diverse cell types, as well as a broad anti-inflammatory function [3].

Relevant to diabetes, SMAD7 plays a central role in regulating the $\beta$-cell proliferation necessary to maintain $\beta$-cell mass [4-6]. This review examines TGF- $\beta$ signaling in the context of pancreatic $\beta$-cell dysfunction and failure in T2D. Specifically, this review highlights potential regulatory roles for TGF- $\beta$ signaling in dedifferentiation- and inflammation-mediated $\beta$-cell dysfunction, in the hope that reviewing past work on this important cytokine family will inform promising new directions in diabetes research.

\section{$\beta$-Cell Dedifferentiation and Dysfunction in T2D}

It is generally accepted that the hyperglycemia of T2D stems from peripheral insulin resistance, which initially stimulates a compensatory $\beta$-cell proliferation and/or increased insulin production. However, it appears that chronic exposure to hyperglycemia--a condition called 
"glucotoxicity"--leads to the accumulation of Reactive Oxygen Species (ROS) in islets. Unfortunately, islets contain extremely low levels of antioxidants, so that ROS accumulation may result in "oxidative stress," a well-known trigger for $\beta$-cell apoptosis [7]. Here, the $\beta$-cell's altered redox state, coupled with other factors such as augmented nutrient-induced insulin synthesis, can lead to endoplasmic reticulum stress-induced apoptosis [8]. The eventual result is a reduced functional $\beta$-cell mass, with resulting further decreases in insulin secretion [9].

In addition to apoptosis, long-term exposure to hyperglycemia may also contribute to diabetic $\beta$-cell failure due to impaired $\beta$-cell proliferation. This impaired replication is thought to lead to a diminished functional $\beta$-cell mass, reduced insulin secretion, and further disruption of glucose homeostasis [10].

Recent evidence suggests that $\beta$-cell dedifferentiation may be an important mechanism for $\beta$-cell failure in the pathogenesis of Type II Diabetes. Talchai et al. reported that the transcription factor FOXO1, which has been shown to coordinately regulate $\beta$-cell mass $[11,12]$ and the $\beta$-cell response to metabolic stress $[13,14]$, is required to prevent $\beta$ cell dedifferentiation, likely through augmenting NeuroD and MafA expression in $\beta$-cells [15]. Moreover, FOXO1 nuclear accumulation, followed by depletion, in $\beta$-cells is identified as a predictive marker of $\beta$-cell dedifferentiation to an endocrine progenitor state that precedes full-blown $\beta$-cell failure in murine diabetes models [10]. A later report building off this study demonstrated that expression levels of the characteristic $\beta$-cell transcriptional regulators MafA, Nkx6.1 and Pdx1 were reduced in diabetic islets from mouse and human pancreata [16].

\section{TGF- $\beta$ protects the $\beta$-cell differentiation state}

TGF- $\beta$ signaling is one of the signaling pathways that influence $\beta$ cell differentiation and function, and impaired TGF- $\beta$ signaling is potentially central to $\beta$-cell dedifferentiation. A 1989 study demonstrated that islets cultured in TGF- $\beta$ increase insulin secretion in a dose-dependent manner. Insulin secretion was maximized when islets were incubated with TGF- $\beta$ isoforms, plus a stimulatory concentration of glucose [17], providing the first evidence that intact TGF- $\beta$ signaling may modulate the $\beta$-cell response to increased glucose levels. Later studies supported this finding: it has been shown that TGF- $\beta$ signaling regulates insulin gene transcription via SMAD3 [18], and that expression levels of components of the TGF- $\beta$ superfamily are tightly regulated by blood glucose levels [19].

SMAD7 appears to have an important regulatory role in protecting the $\beta$-cell transcriptional program and $\beta$-cell function. $\beta$-cell specific overexpression of SMAD7, a downstream inhibitor of TGF- $\beta$ signaling, resulted in temporary and reversible overt diabetes [20]. In this study, hyperglycemia and impaired glucose response were correlated with significant declines in serum and pancreatic insulin levels, as well as with diminished $\beta$-cell expression of MafA, a key insulin transcription regulator [21], and of the $\beta$-cell-cycle regulators p27kip1 and menin. These findings point to a central role for intact TGF- $\beta$ signaling in preserving adequate $\beta$-cell glucose-stimulated insulin secretion and the mature $\beta$-cell transcriptional program, and suggest that the equilibrium achieved in the $\beta$-cell by SMAD7 inhibition of canonical SMAD signaling is delicate.

\section{SMAD7 coordinately regulates $\beta$-cell proliferation and the $\beta$ - cell differentiation state}

Compensatory increases in $\beta$-cell mass following a pancreatic insult or metabolic stress are necessary for proper glucose homeostasis. There is much evidence that this process is tightly controlled. A recent report highlighted a pivotal role for SMAD7 in $\beta$-cell proliferation following partial pancreatectomy; this proliferation was accompanied by transient dedifferentiation to a developmentally immature, PP-fold + state [5]. Moreover, proliferation of $\beta$-cells following pancreatic duct ligation (PDL) is associated with a reduction in insulin, Pdx1, NeuroD1, MafA, and Nkx6.1 gene transcript levels, consistent with the notion that $\beta$-cell proliferation requires some degree of dedifferentiation from a mature transcriptional program [4]. Therefore, $\beta$-cell proliferation and the $\beta$-cell differentiation state appear to be coordinately regulated, and this regulation seems to occur, at least in part, through the SMAD signaling pathway. Based on this observation, we propose two possible mechanisms by which TGF$\beta$ signaling may control the $\beta$-cell differentiation state.

\section{Proposed mechanism 1 for TGF- $\beta$ control of the $\beta$-cell differentiation state: $\beta$-cell cross-talk between TGF- $\beta$ and Insulin/Insulin-like Growth Factor 1 Receptor (IGFR) signaling pathways}

Both TGF- $\beta$ signaling and insulin-receptor/IGFR signaling regulate $\beta$-cell proliferation $[4-6,22]$. Therefore, it is possible that TGF- $\beta$ and insulin receptor /IGFR signaling also interact to regulate the $\beta$-cell differentiation state.

In neuroepithelial cells, TGF- $\beta$ and insulin/IGFR signaling regulate proliferation through interactions between the SMAD- and the phosphoinositide-3-kinase (PI3K) pathways. FOXO family proteins are at the center of this cross-talk, as FOXO transcription factors interact with the SMAD3/SMAD4 complex in the nucleus to activate the cell-cycle inhibitor p21 (CIP1), thus inhibiting proliferation in neuroepithelial and glioblastoma cells [23]. FOXO nuclear translocation and transcriptional regulation is inhibited by phosphorylation by AKT (Protein Kinase B), a downstream molecule in the PI3K pathway; thus, activation of the PI3K pathway by upstream signaling, such as Insulin/IGFR signaling, may inhibit the TGF- $\beta$ cytostatic program by preventing nuclear translocation of FOXO1 [24].

FOXO/Insulin/IGFR signaling cross-talk has important ramifications for $\beta$-cell function. Constitutive negative regulation of FOXO1 transcriptional activity by tonic insulin/IGF-1R signaling has been shown to allow expression of $\mathrm{Pdx}-1$, an important $\beta$ cell transcription factor that is downregulated by nuclear FOXO1 $[11,15,25]$. In other words, a phenotype specific to the $\beta$-cell (i.e. tonic autocrine insulin signaling plus FOXO1 nuclear exclusion) is central to the proper function of the $\beta$-cell. Further experiments may determine whether FOXO1 exerts its protective effects in the $\beta$-cell in part through coordinating cross-talk between the TGF- $\beta$ and insulin/ IGFR proliferation-regulating network (Figure 1). 


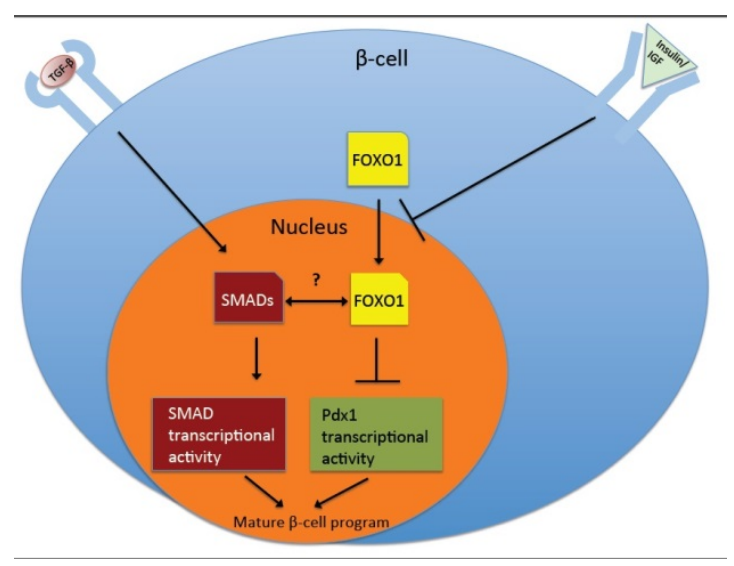

Figure 1: FOXO family proteins may be a point of cross-talk between Insulin/IGFR signaling components and TGF- $\beta$ signaling components in regulating the $\beta$-cell differentiation state.

\section{Proposed mechanism 2 for TGF- $\beta$ control of the $\beta$-cell differentiation state: $\beta$-cell cross-talk between TGF- $\beta$ and EGFR signaling pathways}

Our study of inflammation-induced $\beta$-cell proliferation [4] reported that following PDL, infiltrating macrophages produce both TGF- $\beta 1$ and EGF, which appear to signal to $\beta$-cells. TGF- $\beta 1$ binding stimulates $\beta$-cell proliferation through SMAD7-induced nuclear exclusion of the cell cycle inhibitor p27kip1. Meanwhile, EGF signaling leads to the nuclear exclusion of SMAD2, the net effect of which is to further support $\beta$-cell proliferation. Thus, a TGF- $\beta 1 /$ EGF network induces $\beta$ cell proliferation. This cross-talk may prove to be central in preserving the mature $\beta$-cell differentiation state as well.

Interactions between TGF- $\beta$ and EGF signaling were demonstrated in a 1998 report, which showed a role for EGF in up-regulating expression of the inhibitory SMADs, SMAD6 and SMAD7 in vitro [26]. Likewise, TGF- $\beta 1$ enhances EGF signaling in intestinal epithelial cells via the potentiation of downstream MAPK and AKT [27]. Finally, TGF- $\beta 1$-induced epithelial-to-mesenchymal transition is dually mediated by TGF- $\beta 1$ and EGF signaling [28]. Therefore, overlap between the TGF- $\beta$ and EGF pathways appears to be important for proper cellular function in a variety of tissues, and further study of the $\beta$-cell may establish the relevance of this cross-talk in the prevention and pathogenesis of diabetes.

\section{TGF- $\beta$ Influences Islet Inflammation and $\beta$-Cell Dysfunction}

It is well established that $\mathrm{T} 2 \mathrm{D}$ is characterized by local inflammation in the Islets of Langerhans. A 2002 study demonstrated an important mechanistic link between blood glucose levels and $\beta$-cell dysfunction in the development of T2D, given its previously known role in T1D islets [29]. Elegant in vitro experiments revealed that human islets can respond to hyperglycemic conditions by secreting IL- $1 \beta$, which binds IL-1R in an autocrine manner and activates nuclear factor kappa-light-chain-enhancer of activated $B$ cells (NF- $\kappa \mathrm{B}$ ) signaling, a prominent pathway activating cellular immune responses
[30]. The downstream effects of this signaling included FAS receptor upregulation and $\beta$-cell apoptosis.

Interestingly, hyperglycemic Psammomys obesus (diabetic sand rat) exhibited aberrant expression of IL- $1 \beta$ in islet $\beta$-cells, as well as diminished insulin expression, indicating that glucotoxic islet inflammation may impair $\beta$-cell function. A later study reported that transgenic mice expressing a $\beta$-cell specific NF- $\kappa B$ inhibitor were virtually resistant to streptozotocin-induced diabetes and concomitant inflammation, suggesting that NF- $\mathrm{KB}$ signaling mediates the damaging effect on $\beta$-cells of streptozotocin and possibly other diabetogenic agents [31]. These results are consistent with reports that $\beta$-cell NF- $\kappa B$ signaling mediates $\beta$-cell apoptosis [32], and that inhibition of NF- $\kappa B$ signaling in $\beta$-cells protects against islet graft rejection [33]. Together, these findings offer a mechanistic link between glucose sensing and $\beta$ cell death in the context of hyperglycemia, and suggest that a similar pathway influences the survival prospects of transplanted islets.

Glucotoxic islet inflammation may trigger a more complex $\beta$-cell response than simply apoptosis. An intriguing new study demonstrated that diabetic mice with a transgenic $\beta$-cell insulin secretory impairment respond to the resulting hyperglycemic conditions with primarily a $\beta$-cell dedifferentiation to an insulin-/ neurogenin3+ state [34]. Restoring normoglycemia with insulin therapy prompted these $\beta$-cells to redifferentiate to an insulinsecreting phenotype. Possible mechanisms underlying this $\beta$-cell dedifferentiation model are uncertain, but it seems likely that hyperglycemia induces glucotoxicity in these transgenic mice, at least in part through the NF- $\mathrm{kB}$ inflammatory pathway. Western blot and immunohistochemistry studies of the diabetic mouse islets used could conclusively determine whether increased islet IL- $1 \beta$ expression and IL-1R signaling play a role in the $\beta$-cell dedifferentiation observed. In that case, NF- $\kappa B$ signaling would be implicated, not only in triggering $\beta$-cell apoptosis in response to high glucose levels, but also in stimulating adaptive $\beta$-cell dedifferentiation. This acute dedifferentiation represents a novel pathway in $\beta$-cell biology and the pathogenesis of T2D.

TGF- $\beta$ signaling may have a role in this glucose-induced inflammation and $\beta$-cell failure. Microarray and rt-PCR studies revealed that transcription of several TGF- $\beta$ superfamily genes are tightly regulated by glucose concentration, including those encoding bone morphogenetic protein 5 (BMP5), TGF- $\beta$, SMAD7, and, most strikingly, prostate-derived factor (PDF) [19]. Likewise, an investigation of impaired TGF- $\beta$ signaling in the context of exocrine fibrosis (an inflammatory process modeling chronic pancreatitis) led to hyperglycemia and diabetic $\beta$-cell failure, suggesting that intact TGF- $\beta$ signaling plays an important role in modulating the $\beta$-cell's response to inflammatory stimuli [35].

Cross-talk between NF- $\kappa \mathrm{B}$ and TGF- $\beta$ signaling is tissue- and cellspecific, and very little is known about the interaction of these pathways in the $\beta$-cell. However, numerous studies have clarified cross-talk mechanisms between TGF- $\beta$ and NF- $\kappa B$ in non-pancreatic tissue. In keratinocytes, TGF- $\beta 1$ regulates NF- $\kappa B$-dependent gene transcription. Similarly, interactions between the TGF- $\beta$ downstream regulators SMAD2 and SMAD3 with a subunit of the NF- $\kappa B$ upstream signal transducer I $\mathrm{K} B$ kinase, I $\mathrm{I} B$ kinase $\alpha(\mathrm{IKK} \alpha)$, regulates keratinocyte differentiation [36] and proliferation in stratified epithelia [37]. Also, SMAD3 interacts with the NF-kB subunit p52 to regulate transcriptional activity in epithelial and fibroblast-like cells [38], while similar interactions take place in the regulation of an ECMrelated gene in fibroblasts [39] and in the regulation of ECM- 
degrading enzymes in monocytes/macrophages [40]. NF- $\kappa \mathrm{B}$ is reported to have an inhibitory effect on TGF- $\beta$ signaling by activating the inhibitory SMAD7 [41]; conversely, TGF- $\beta 1$ signaling negatively regulates NF- $\kappa \mathrm{B}$ activation in the gut, and SMAD7 potentiates gut NF$\kappa \mathrm{B}$ signaling [42]. In sum, there is robust cross-talk between TGF- $\beta 1$ and NF- $\kappa B$ signaling that mediates a wide range of important cellular processes in multiple tissues. It seems likely that TGF- $\beta$ signaling, via downstream SMAD molecules, regulates NF- $\kappa B$-mediated glucotoxic effects such as $\beta$ cell apoptosis or dedifferentiation, but this hypothesis requires direct experimental evidence to be validated.

\section{TGF- $\beta$ may Influence Progression of Pre-diabetes to Overt T2D}

Ciccone et al. have emphasized the importance of recognizing and treating symptoms of pre-diabetes before they constitute overt T2D [43]. These authors have noted that alterations in the incretin hormones glucagon-like peptide-1 (GLP-1) and glucose-dependent insulinotropic polypeptide (GIP), which serve to increase $\beta$-cell insulin secretion, may contribute to the onset of pre-diabetes, and ultimately, overt T2D.

There is evidence that GLP-1 signaling and TGF- $\beta$ signaling interact synergistically in the differentiation of endocrine cells during development [44]. Therefore, it is reasonable to hypothesize that crosstalk between GLP-1 and TGF- $\beta$ signaling pathways influences normal adult $\beta$-cell function, and that disruption of this cross-talk through modifications to either of the signaling pathways might influence the progression to pre-diabetes. Further experiments will substantiate this hypothesis.

\section{Conclusions}

TGF- $\beta$ signaling via the intracellular SMAD network is central to $\beta$ cell function and the health of the organism (Table 1). Broadly, TGF- $\beta$ signaling renders $\beta$-cells exquisitely sensitive to insulin demand and helps orchestrate proper insulin transcription. 0 The TGF- $\beta$ pathway also preserves the appropriate $\beta$-cell transcriptional program by influencing MafA expression. Moreover, this pathway coordinates compensatory $\beta$-cell expansion, which has been shown to be associated with transient dedifferentiation to a developmentally immature state. We propose that future studies on cross-talk between TGF- $\beta$, EGF, and Insulin/IGFR pathways will yield insights into the unique ways $\beta$-cells dually coordinate proliferation and the differentiation state.

During the pathogenesis of T2D, $\beta$-cells respond to hyperglycemia by instigating an inflammatory NF- $\kappa \mathrm{B}$ dependent apoptotic program. Given the central role of TGF- $\beta$ signaling in coordinating the $\beta$-cell's response to glucose, and given the known role of TGF- $\beta$ signaling in modulating cellular responses to inflammatory signals, it is likely that TGF- $\beta$ signaling also regulates NF- $\kappa B$-mediated $\beta$-cell apoptosis and adaptive dedifferentiation following hyperglycemia. Future studies examining TGF- $\beta$ signaling in this context might reveal a novel role for TGF- $\beta$ signaling in the development of T2D.

A more nuanced understanding of the role of TGF- $\beta$ signaling in preserving $\beta$-cell differentiation state and regulating the $\beta$-cell response to chronic hyperglycemia may inform clinical interventions. Most likely, these mechanistic insights will prompt investigation of targeted pharmacological interventions geared to preserving $\beta$-cell differentiation state and reducing islet inflammation in pre-diabetic patients.

\begin{tabular}{|l|l|}
\hline $\begin{array}{l}\text { TGF- } \beta \text { signaling components are } \\
\text { known to regulate: }\end{array}$ & $\begin{array}{l}\text { TGF- } \beta \text { signaling components may } \\
\text { regulate: }\end{array}$ \\
\hline Insulin gene transcription & $\beta$-cell response to hyperglycemia: \\
\hline Glucose-stimulated insulin secretion & Adaptive dedifferentiation \\
\hline $\begin{array}{l}\text { Compensatory } \quad \beta \text {-cell proliferation } \\
\text { accompanied by transient } \\
\text { dedifferentiation to a PP+ state }\end{array}$ & $\begin{array}{l}\text { NF-KB-mediated } \beta \text {-cell apoptosis in the } \\
\text { context of islet inflammation }\end{array}$ \\
\hline $\begin{array}{l}\text { Mature } \beta \text {-cell transcriptional program } \\
\text { (through MafA expression) }\end{array}$ & $\begin{array}{l}\text { The left-hand column summarizes established findings; the right-hand } \\
\text { column offers hypotheses for further studies. }\end{array}$ \\
\hline
\end{tabular}

Table 1: A visual summary of the role of TGF- $\beta$ signaling in $\beta$-cell function.

\section{Acknowledgments}

Special thanks to Xiangwei Xiao and Lauren Peirish for helpful comments on the manuscript. This work was supported, in whole or in part, by the Cochrane-Weber Endowed Fund in Diabetes Research Grant NO19831 (to Xiangwei Xiao), and NIH Grant R01 DK098196 (to George K. Gittes), and the Children's Hospital of Pittsburgh Foundation.

\section{References}

1. Massagué J, Gomis RR (2006) The logic of TGFbeta signaling. below FEBS Lett 580: 2811-2820.

2. Shi Y, Massagué J (2003) Mechanisms of TGF-beta signaling from cell membrane to the nucleus. Cell 113: 685-700.

3. Yan X, Liu Z, Chen Y (2009) Regulation of TGF-beta signaling by Smad7. below Acta Biochim Biophys Sin (Shanghai) 41: 263-272.

4. Xiao X, Gaffar I, Guo P, Wiersch J, Fischbach S, et al. (2014) M2 macrophages promote beta-cell proliferation by up-regulation of SMAD7. Proc Natl Acad Sci U S A 111: E1211-1220.

5. El-Gohary Y, Tulachan S, Wiersch J, Guo P, Welsh C, et al. (2014) A smad signaling network regulates islet cell proliferation. Diabetes 63: 224-236.

6. Xiao X, Wiersch J, El-Gohary Y, Guo P, Prasadan K, et al. (2013) TGF $\beta$ receptor signaling is essential for inflammation-induced but not $\beta$-cell workload-induced $\beta$-cell proliferation. Diabetes 62: 1217-1226.

7. Robertson RP (2004) Chronic oxidative stress as a central mechanism for glucose toxicity in pancreatic islet beta cells in diabetes. J Biol Chem 279: 42351-42354.

8. Eizirik DL, Cardozo AK, Cnop M (2008) The role for endoplasmic reticulum stress in diabetes mellitus. Endocr Rev 29: 42-61.

9. Dor Y, Glaser B (2013) $\beta$-cell dedifferentiation and type 2 diabetes. $\mathrm{N}$ Engl J Med 368: 572-573.

10. Talchai C, Xuan S, Lin HV, Sussel L, Accili D (2012) Pancreatic $\beta$ cell dedifferentiation as a mechanism of diabetic $\beta$ cell failure. Cell 150: 1223-1234.

11. Kitamura T, Nakae J, Kitamura Y, Kido Y, Biggs WH 3rd, et al. (2002) The forkhead transcription factor Foxol links insulin signaling to Pdx1 regulation of pancreatic beta cell growth. J Clin Invest 110: 1839-1847.

12. Okamoto H, Hribal ML, Lin HV, Bennett WR, Ward A, et al. (2006) Role of the forkhead protein FoxO1 in beta cell compensation to insulin resistance. J Clin Invest 116: 775-782. 
Citation: Fischbach S, Gittes GK (2014) The Role of TGF- $\beta$ Signaling in $\beta$-Cell Dysfunction and Type 2 Diabetes: A Review. J Cytol Histol 5:

Page 5 of 5

13. Kawamori D, Kaneto H, Nakatani Y, Matsuoka TA, Matsuhisa M, et al. (2006) The forkhead transcription factor Foxol bridges the JNK pathway and the transcription factor PDX-1 through its intracellular translocation. J Biol Chem 281: 1091-1098.

14. Martinez SC, Cras-Méneur C, Bernal-Mizrachi E, Permutt MA (2006) Glucose regulates Foxol through insulin receptor signaling in the pancreatic islet beta-cell. Diabetes 55: 1581-1591.

15. Kitamura YI, Kitamura T, Kruse JP, Raum JC, Stein R, et al. (2005) FoxO1 protects against pancreatic beta cell failure through NeuroD and MafA induction. Cell Metab 2: 153-163.

16. Guo S, Dai C, Guo M, Taylor B, Harmon JS, et al. (2013) Inactivation of specific $\beta$ cell transcription factors in type 2 diabetes. J Clin Invest 123 : 3305-3316.

17. Totsuka Y, Tabuchi M, Kojima I, Eto Y, Shibai H, et al. (1989) Stimulation of insulin secretion by transforming growth factor-beta. Biochem Biophys Res Commun 158: 1060-1065.

18. Lin HM, Lee JH, Yadav H, Kamaraju AK, Liu E, et al. (2009) Transforming growth factor-beta/Smad3 signaling regulates insulin gene transcription and pancreatic islet beta-cell function. J Biol Chem 284: 12246-12257.

19. Shalev A, Pise-Masison CA, Radonovich M, Hoffmann SC, Hirshberg B et al., (2002) Oligonucleotide microarray analysis of intact human pancreatic islets: identification of glucose-responsive genes and a highly regulated TGFbeta signaling pathway. Endocrinology 143: 3695-3698.

20. Smart NG, Apelqvist AA, Gu X, Harmon EB, Topper JN, et al. (2006) Conditional expression of Smad7 in pancreatic beta cells disrupts TGFbeta signaling and induces reversible diabetes mellitus. PLoS Biol 4: e39.

21. Zhao L, Guo M, Matsuoka TA, Hagman DK, Parazzoli SD, et al. (2005) The islet beta cell-enriched MafA activator is a key regulator of insulin gene transcription. J Biol Chem 280: 11887-11894.

22. Johnson JD, Alejandro EU (2008) Control of pancreatic beta-cell fate by insulin signaling: The sweet spot hypothesis. Cell Cycle 7: 1343-1347.

23. Seoane J, Le HV, Shen L, Anderson SA, Massagué J (2004) Integration of Smad and forkhead pathways in the control of neuroepithelial and glioblastoma cell proliferation. Cell 117: 211-223.

24. Vivanco I, Sawyers CL (2002) The phosphatidylinositol 3-Kinase AKT pathway in human cancer. Nat Rev Cancer 2: 489-501.

25. Harbeck MC, Louie DC, Howland J, Wolf BA, Rothenberg PL (1996) Expression of insulin receptor mRNA and insulin receptor substrate 1 in pancreatic islet beta-cells. Diabetes 45: 711-717.

26. Afrakhte M1, Morén A, Jossan S, Itoh S, Sampath K, et al. (1998) Induction of inhibitory Smad6 and Smad7 mRNA by TGF-beta family members. Biochem Biophys Res Commun 249: 505-511.

27. Uttamsingh S, Bao X, Nguyen KT, Bhanot M, Gong J, et al. (2008) Synergistic effect between EGF and TGF-betal in inducing oncogenic properties of intestinal epithelial cells. Oncogene 27: 2626-2634.

28. Docherty NG, O'Sullivan OE, Healy DA, Murphy M, O'neill AJ, et al (2006) TGF-betal-induced EMT can occur independently of its proapoptotic effects and is aided by EGF receptor activation. Am J Physiol Renal Physiol 290: F1202-1212.

29. Maedler K, Sergeev P, Ris F, Oberholzer J, Joller-Jemelka HI, et al. (2002) Glucose-induced beta cell production of IL-1beta contributes to glucotoxicity in human pancreatic islets. J Clin Invest 110: 851-860.
30. Li Q, Verma IM (2002) NF-kappaB regulation in the immune system. Nat Rev Immunol 2: 725-734.

31. Eldor R, Yeffet A, Baum K, Doviner V, Amar D, et al. (2006) Conditional and specific NF-kappaB blockade protects pancreatic beta cells from diabetogenic agents. Proc Natl Acad Sci U S A 103: 5072-5077.

32. Melloul D (2008) Role of NF-kappaB in beta-cell death. Biochem Soc Trans 36: 334-339.

33. Eldor R, Abel R, Sever D, Sadoun G, Peled A, et al. (2013) Inhibition of nuclear factor- $\kappa \mathrm{B}$ activation in pancreatic $\beta$-cells has a protective effect on allogeneic pancreatic islet graft survival. PLoS One 8: e56924.

34. Wang Z, York NW, Nichols CG, Remedi MS (2014) Pancreatic $\beta$ cell dedifferentiation in diabetes and redifferentiation following insulin therapy. Cell Metab 19: 872-882.

35. Sanvito F, Nichols A, Herrera PL, Huarte J, Wohlwend A, et al. (1995) TGF-beta 1 overexpression in murine pancreas induces chronic pancreatitis and, together with TNF-alpha, triggers insulin-dependent diabetes. Biochem Biophys Res Commun 217: 1279-1286.

36. Descargues P, Sil AK, Sano Y, Korchynskyi O, Han G, et al. (2008) IKKalpha is a critical coregulator of a Smad4-independent TGFbetaSmad2/3 signaling pathway that controls keratinocyte differentiation. Proc Natl Acad Sci U S A 105: 2487-2492.

37. Marinari B, Moretti F, Botti E, Giustizieri ML, Descargues P, et al. (2008) The tumor suppressor activity of IKKalpha in stratified epithelia is exerted in part via the TGF-beta antiproliferative pathway. Proc Natl Acad Sci U S A 105: 17091-17096.

38. López-Rovira T, Chalaux E, Rosa JL, Bartrons R, Ventura F (2000) Interaction and functional cooperation of NF-kappa B with Smads. Transcriptional regulation of the junB promoter. J Biol Chem 275: 28937-28946.

39. Kon A, Vindevoghel L, Kouba DJ, Fujimura Y, Uitto J, et al. (1999) Cooperation between SMAD and NF-kappaB in growth factor regulated type VII collagen gene expression. Oncogene 18: 1837-1844.

40. Ogawa K, Chen F, Kuang C, Chen Y (2004) Suppression of matrix metalloproteinase-9 transcription by transforming growth factor-beta is mediated by a nuclear factor-kappaB site. Biochem J 381: 413-422.

41. Bitzer M von Gersdorff G, Liang D, Dominguez-Rosales A, Beg AA, et al. (2000) A mechanism of suppression of TGF-beta/SMAD signaling by NF-kappa B/RelA. Genes Dev 14: 187-197.

42. Monteleone G, Mann J, Monteleone I, Vavassori P, Bremner R, et al. (2004) A failure of transforming growth factor-betal negative regulation maintains sustained NF-kappaB activation in gut inflammation. J Biol Chem 279: 3925-3932.

43. Marco Matteo Ciccone, Pietro Scicchitano, Matteo Cameli, Annagrazia Cecere, Francesca Cortese, et al., Endothelial function in Pre-diabetes, Diabetes and Diabetic Cardiomyopathy: A Review, J Diabetes Metab 2014. 5: 364 .

44. Tei E, Mehta S, Tulachan SS, Yew H, Hembree M, et al. (2005) Synergistic endocrine induction by GLP-1 and TGF-beta in the developing pancreas. Pancreas 31: 138-141. 